\title{
Re-expansion Pulmonary Edema after Chest Drainage for Pneumothorax; Evaluation of Risk Factors in 630 Episodes
}

\author{
Motoki SAKURABA*, Taijiro MISHINA, Akihiko TANAKA \\ Sapporo City General Hospital, Department of General Thoracic Surgery, Hokkaido 060-8604, Japan \\ *Corresponding Author: Motoki SAKURABA, Sapporo City General Hospital, Department of General \\ Thoracic Surgery 1-1, West13 North11, Chuou-ku, Sapporo city, Hokkaido 060-8604, Japan.
}

\begin{abstract}
Background: Re-expansion pulmonary edema (RPE) is a rare complication after chest drainage of spontaneous pneumothoraxs. We report RPE cases in our hospital over 5 years.

Methods: Clinical records of patients treated for spontaneous pneumothorax from April 2012 to March 2019 at our institute were retrospectively reviewed. Chest tube placement was performed 630 times. RPE is diagnosed by chest $x$-ray or chest computed tomography within 24 to 48 hours after drainage. Patients were categorized into RPE and non-RPE groups.
\end{abstract}

Results: Forty five (7.1\%) of 630 treated cases were diagnosed with RPE (15 [2.4\%] symptomatic RPE, 30 [4.8\%] asymptomatic). Forty cases of 45 were 3rd degrees in lung collapse classification and 11 cases showed total lung collapse. Oxygen was administered in 15 cases. Thirteen cases presented with dyspnea after intense cough. Periods from onset to drainage, cough and aterectasis or lung collapse classification are significantly difference between RPE and non-RPE groups on univariate analysis and multivariate analysis

Conclusions: Large pneumothorax or total lung collapse of greater than 4 days of duration is associated with RPE development in the presence of intense cough. Management of cough after pneumothorax treatment may be a potential therapy to prevent RPE.

Abbreviations: RPE, Re-expansion pulmonary edema

Keywords: Re-expansion pulmonary edema, Primary spontaneous pneumothorax, Chest tube drainage

\section{INTRODUCTION}

Re-expansion pulmonary edema (RPE) is a complication of tube thoracostomy for pneumothorax and massive pleural effusion, and was initially reported after spontaneous pneumothorax by Carlson in 1958 [1]. The incidence of RPE for spontaneous pneumothorax treatments ranges from $0.9 \%$ to 29.8\% [2, 3]. Although most patients with RPE recover without any treatment, it can lead to prolonged hospital stay, increased chest discomfort, dyspnea, and in severe cases hemodynamic and respiratory instability, making early recognition and understanding of associated risk factors of utmost importance. We aim to describe the incidence, risk factors, and outcomes for RPE cases at our institution.

\section{Patients And Methods}

We analyzed medical records of all patients treated for spontaneous pneumothorax between
April 2012 and March 2019 at Sapporo City General Hospital Pneumothorax Center. Chest tube drainage was performed 630 times. Cases complicated by 13 hemopneumothorax, 32 traumatic pneumothorax and 8 iatrogenic pneumothorax were excluded. RPE was diagnosed by chest $\mathrm{x}$-ray or chest computed tomography within 24 to 48 hours of drainage. We used modified lung collapse classification in Japan society of pneumothorax and cystic disease on chest x-ray. First degree shows that top of lung locates the clavicle or head side. Second degree shows that the top of lung locates below clavicle or the width of the lungs is located two-thirds of whole or more. Third degree shows that the width of the lungs is located two-thirds of whole or less. According to our experience, for the patient suffering from a pneumothorax sized more than $40 \%$ (Third degree of collapse classification) during more than 24 hours steroid were administered 
intravenously before chest drainage in advance and continuous suction were not performed. Under such condition patients were categorized into groups with RPE and non-RPE. Age, gender, time from pneumothorax onset to drainage, smoking habits, lung collapse classification, presence of atelectasis (one lobe or more), cough after treatment, steroid administration before drainage, drain tube size, and continuous suction were compared between the 2 groups. 20Fr trocar catheter or $12 \mathrm{Fr}$ aspiration kit were used for chest drainage.

\section{Analysis}

All analysis were performed using IBM SPSS Statistics for Windows, Version 22.0 (IBM Corp., Armonk, NY, USA). Continuous variables were analyzed using Mann-Whitney U test. Categorized variables were analyzed using $\chi 2$ test or Fisher's exact probability test as appropriate. Statistical significance was set at $p<0.05$. To determine risk factors for RPE, variables with $\mathrm{p}<0.05$ in univariate analysis were used in multiple logistic regression.

\section{ReSUlts}

The characteristics of all patients show Table.1. The mean age of the patients was 39.9 (range 12 to 98) years. The mean duration from onset of pneumothorax to duration was 3.6 (range 1 to 30) days. Steroid were administered intravenously before chest drainage for 169 $(26.8 \%)$ episodes. Forty-five $(7.1 \%)$ of the 630 cases were diagnosed as RPE. Fifteen $(2.4 \%)$ cases were defined as symptomatic RPE, and 28 $(4.8 \%)$ cases were asymptomatic. Treatment ranged 1 to 13 days (average: 4.4 days) from onset of pneumothorax in the RPE group. Forty cases of 45 were 3 rd degrees in lung collapse classification and 11 cases showed total lung collapse. In all cases, $100 \mathrm{mg}$ of hydrocortisone sodium succinate was intravenously administered before drainage. Time from pneumothorax onset to drainage, lung collapse classification, and cough, were significantly difference between 2 groups $(\mathrm{p}<0.05)$ in univariate analysis and multivariate analysis (Table.2).

Treatment of symptomatic RPE and outcomes are shown in Table 3. All symptomatic patients required additional oxygen administration for an average of 1 day after RPE development. All patients were alive without any complications during until a discharge.

Table1. Patient characteristics

\begin{tabular}{|l|l|c|}
\hline Cases & & 630 \\
\hline Age & & $12-98(39.9)$ \\
\hline Gender & Male/Female & $549 / 81$ \\
\hline Time from pneumothorax onset to drainage (day) & (mean) & $1-30(3.6)$ \\
\hline Smoking & Yes/No/Unknown & $341 / 285 / 4$ \\
\hline Lung collapse classification & I,II/III & $384 / 246$ \\
\hline Aterectasis & Yes/No & $107 / 523$ \\
\hline Cough & Yes/No & $52 / 578$ \\
\hline Steroid administration before drainage & Yes/No & $169 / 461$ \\
\hline Drain Tube & 2OFr/12Fr & $570 / 60$ \\
\hline Continuous Suction & Yes/No & $579 / 51$ \\
\hline
\end{tabular}

Table2. Risk factors of RPE in univariate analysis and multivariate analysis

\begin{tabular}{|c|c|c|c|c|c|c|c|}
\hline & & REPE & non-REPE & univariate analysis & \multicolumn{3}{|c|}{ multivariate analysis } \\
\hline & & $n=45$ & $\mathrm{n}=585$ & $\mathrm{p}$ & $\mathrm{p}$ & OR & $95 \% \mathrm{CI}$ \\
\hline Age & & $13-93(42.0)$ & $12-98(37.8)$ & 0.068 & & & \\
\hline Gender & Male/Female & $37 / 8$ & $512 / 73$ & 0.3375 & & & \\
\hline $\begin{array}{l}\text { Time from } \\
\text { pneumothorax } \\
\text { onset to } \\
\text { drainage (day) }\end{array}$ & $($ mean $)$ & $1-13(4.4)$ & $1-30(2.8)$ & $<0.001$ & 0.002 & 1.117 & $1.043-1.196$ \\
\hline Smoking & Yes/No & $29 / 16$ & $312 / 269$ & 0.2207 & & & \\
\hline $\begin{array}{l}\text { Lung collapse } \\
\text { classification }\end{array}$ & I,II/III & $5 / 40$ & $379 / 206$ & $<0.001$ & $<0.001$ & 10.122 & $3.623-28.282$ \\
\hline Aterectasis & Yes/No & $40 / 5$ & $67 / 518$ & $<0.001$ & $<0.001$ & 3.01 & $1.977-4.582$ \\
\hline Cough & Yes/No & $18 / 27$ & $34 / 551$ & $<0.001$ & $<0.001$ & 27.914 & $10.315-75.538$ \\
\hline Drain Tube & $20 \mathrm{Fr} / 12 \mathrm{Fr}$ & $41 / 4$ & $529 / 56$ & 0.7744 & & & \\
\hline
\end{tabular}


Re-expansion Pulmonary Edema after Chest Drainage for Pneumothorax; Evaluation of Risk Factors in 630 Episodes

Table3. Symptom, treatment and outcome of symptomatic RPE

\begin{tabular}{|l|c|c|}
\hline & & $\mathrm{n}=15$ \\
\hline Steroid administration before drainage & Yes/No & $15 / 0$ \\
\hline Continuous Suction & Yes/No & $1 / 14$ \\
\hline Cough & Yes/No & $15 / 0$ \\
\hline Oxygen device & Nasal highflow & 1 \\
\hline & Non-rebreather mask & 5 \\
\hline & Nasa canula & 9 \\
\hline Time to recover & (hours) & $0.5-44$ \\
\hline & average & 23.4 \\
\hline Mortality & & 0 \\
\hline
\end{tabular}

\section{DISCUSSION}

The incidence of RPE for spontaneous pneumothorax treatment ranges from $0.9 \%$ to $29.8 \%[2,3]$. However, a recent report in Japan indicated an incidence of $14.6-15.6 \%[4,5]$. Kim et al report that actual RPE develops in $29.8 \%$ of patients and symptomatic RPE incidence is $19 \%$ [3]. In our study, the incidence of RPE was $7 \%$, and symptomatic RPE was $2.4 \%$, which is smaller than prior reports, and may be related to our drainage management. First, $100 \mathrm{mg}$ of hydrocortisone sodium succinate was administered intravenously for pneumothorax patients with large lung collapse before chest drainage. Second, after insertion of chest tube, patients were not treated with continuous suction but rather underwent water seal for 24 hours. In addition, patients were restricted from activity for one day.

In cases with large lung collapse for 3 days or more, it was previously reported that RPE occurred within 24 hours due to rapid lung expansion, and the mortality rate is $22 \%$ [6]. However, mortality rates are decreasing due to advances in early diagnosis and treatment. In our study, patients with symptomatic RPE required oxygen, but all recovered without further complications. Currently, we does not experience the case of ventilator management, and it has become possible to teat by administrating high-flow oxygen. In our study, of the 15 cases that required oxygen supplementation, there were $9 / 15$ cases of nasal canula use, $5 / 15$ cases of non-rebreather mask use, and 1/15 cases of nasal high-flow use.

Previously reported risk factors of RPE include young age [4], large pneumothorax [4,7], pneumothorax for 3 days or more [8], rapidly pulmonary expansion $[7,9,10]$ and continuous suction [6]. In our study, risk factor for development of RPE included pneumothorax for 4 days or more prior to treatment and with large pneumothorax, especially aterectasis involving more than one lobe. We also found that incidence of cough increased after chest drainage, likely due to the underlying rapidly pulmonary expansion. The expanding lung by cough induced sever cough, in result rapidly pulmonary expansion induced RPE. It is also thought that continuous suction may be an initial cause leading to rapidly pulmonary expansion, and its avoidance may lead to better outcomes after pneumothorax treatment. Morioka et al previously reported that cough was the most frequent symptom in RPE patients, and cough preceded severe RPE, as well [5].

Steroids were administered with the aim of decreasing pulmonary vascular permeability as part of the treatment of RPE. However, the effectiveness of intravenous steroid use is unclear. Steroids are reported to contribute to the suppression of humoral factors leading to vascular endothelial damage, as well as the suppression of irreversible fibrosis due to diffuse alveolar damage [11]. It may be related to the steroid administration to have lowered the frequency of the RPE onset in our center. However, their usefulness was not proved in our study.

There were several limitations in our study. First, the study was retrospective and single centered, whereas a prospective study in multicentered study would allow for more generalizable data and analysis. Second, the diagnostic methods of RPE were not uniform. Almost patients with initial pneumothorax underwent chest computed tomography the next day after chest drainage, but patients with two or more pneumothorax often underwent chest $\mathrm{x}$ ray. In these patient, RPE might be overlooked. Finally, the retrospective nature of the study limits the information available as some medical records may be lacking in details regarding inpatient symptoms, management, or outcomes.

\section{Conclusions}

Large pneumothorax or lung collapse of greater than 4 days of duration is associated with RPE 
Re-expansion Pulmonary Edema after Chest Drainage for Pneumothorax; Evaluation of Risk Factors in 630 Episodes

development in the presence of intense cough. Management of cough just after the thoracic drainage to become the cause of pulmonary rapidly expansion after pneumothorax treatment may be a potential therapy to prevent RPE.

\section{CONFLICT OF INTEREST}

The authors declare no conflicts of interest

\section{FUNDING}

There is no source of funding to report for this study.

\section{ETHICS APPROVAL}

This retrospective study was approved by the ethics committee of our institution (IRB No. R01-059-609).

\section{REFERENCES}

[1] Carson RI, Classen KL, Gollan F, Gobbel WG Jr, Sherman DE, Christensen RO., Pulmonary edema following the rapid reexpansion of a totally collapsed kung due to a pneumothorax: A clicical and experimental study. Surg orum 9:361-367, 1958

[2] Rozenman J, Yellin A, Simansky DA, Shiner RJ., Re-expansion pulmonary oedema following spontaneous pneumothorax. Respir Med 90: 235-238, 1996

[3] Kim YK, Kim H, Lee CC, Choi HJ, Lee KH, Hwang SO, Oh JH, Lee YH, Singer AL., New classification and clinical characteristics of reexpansion pulmonary edema after treatment of spontaneous pneumothorax. Am J Emerg Med 27: 961-967, 2009

[4] Matsuura Y, Nomimura T, Murakami H, Matsushima T, KakehashiM,Kajihara H., Clinical analysis of reexpansion pulmonary edema. Chest 100: 1562-1569, 1991

[5] Morioka H, Takada K, Masumoto S, Kojima E, Iwata S, Okachi S., Re-expansion pulmonary edema: evaluation of risk factors in 173 episodes of spontaneous pneumothorax. Resp Inv 51: 35-39, 2003

[6] Mahfood S, Hix WR, Aaron BL, Blaes P, Watson DC.,Reexpansion pulmonary edema. AnnThorac Surg 45: 340-345, 1988

[7] Sherman AC., Reexpansion pulmonary edema: a case report and review of the current literature. J Emeg Med 24: 23-27, 2003

[8] Sohara Y., Reexpansion pulmonary edema. Ann Thoracic Cardiovasc Surg 14: 205-209, 2008

[9] Murphy K, Tomlanovich MC., Unilateral pulmonary edema after drainage of spontaneous pneumothorax: case report and review of the world literature. J Emerg Med 1: 29-36, 1983

[10] MacDuff A, Arnold A, Harvey J., BTS Pleural Disease Guidekine Group. Management of spontaneous pneumothorax: British Thoracic Society Pleural Disease Guidline 2010. Thorax 65(suppl): ii18-31, 2010

[11] Honmou S, Arikura J, Yamazaki H, Aoki H, Nagase A., Bilateral re-expansion pulmonary edema following video-assisted thoracoscopic surgery for pneumothorax. J Jap Assoc Chest Surg 22: 645-648, 2008

Citation: Motoki SAKURABA, Taijiro MISHINA, Akihiko TANAKA. "Re-expansion Pulmonary Edema after Chest Drainage for Pneumothorax; Evaluation of Risk Factors in 630 Episodes”. ARC Journal of Surgery. 2021; 7(1):9-12. DOI: https://doi.org/10.20431/2455-572X.0701002.

Copyright: (C) 2021 Authors. This is an open-access article distributed under the terms of the Creative Commons Attribution License, which permits unrestricted use, distribution, and reproduction in any medium, provided the original author and source are credited. 